\title{
Prevalence of Occult Hepatitis B Virus Infection in Hemodialysis Patients Using Nested PCR
}

\author{
Elham Samadi ${ }^{1}$, Hessam Mirshahabi*1, ${ }^{*}$ ima Motamed $^{2}$,Hamid Sadeghi ${ }^{1}$
}

\begin{abstract}
Background: Occult hepatitis B infection (OBI) is defined as the lack of detectable HBsAg in serum, despite the presence of intrahepatic viral DNA, and low levels of covalently closed circular DNA (cccDNA). Since the hemodialysis patients are at a greater disadvantage if they are a carrier of Hep B, as it can lead to OBI this study was designed to determine the prevalence of OBI in hemodialysis patients residing in Zanjan, Iran.

Methods: We conducted an anti-HBc test (ELISA) on $166 \mathrm{HBsAg}$ negative hemodialysis patient samples. OBI was evaluated using seropositive (anti-HBc and/or anti-HBs) and seronegative (anti-HBc and anti-HBs) using nested PCR.

Results: Out of the total hemodialysis patients sampled, the study consisted of $58.4 \%$ male and $41.6 \%$ female participants. The age of the study group ranged from 58.89 \pm 15.49 , and had received approximately $28.27 \pm 27.43$ years of dialysis. Additionally, $5.4 \%$ of patients had a history of blood transfusions, while $58.4 \%$ were vaccinated against the hepatitis B virus (HBV). Moreover, $23.5 \%$ patients were anti-HBc positive, while $76.5 \%$ patients tested negative. Lastly, $66.3 \%$ of the patients were positive for anti-HBs, whereas $33.7 \%$ were negative for antiHBs. Overall, the study revealed that the prevalence of OBI was $6 \%$, and HBV DNA was detected in $2.1 \%$ of individuals who were vaccinated against hepatitis $\mathrm{B}(\mathrm{p}<0.01)$.

Conclusions: Though no significant difference between the prevalence of OBI to the patients' age, sex, duration of dialysis, or history of blood transfusion was identified, however, a strong correlation between the prevalence of $\mathrm{OBI}$ to $\mathrm{HBV}$ vaccination was found.
\end{abstract}

Keywords: ELISA, Hemodialysis, Nested PCR, Occult hepatitis B infection.

\section{Introduction}

Chronic hepatitis B infection is a major health concern that affects 400 million people worldwide, especially developing nations (2). Unfortunately, there is a higher risk of developing cirrhosis, hepatic insufficiency, and hepatocellular carcinoma (HCC) in hepatitis B carriers. Each year, it is estimated that 200,000 deaths result from cirrhosis alone, and 300,000 deaths are related to HCC worldwide (2). However, most hepatitis B virus carriers may not experience any of the above liver complications, in fact, majority of those individuals (15 to $40 \%$ ) may be susceptible to liver disease (3). In Iran, specifically, the prevalence of hepatitis B is $2.14 \%$ (2.55\% in men and $2.03 \%$ in women), and the rate of infection is estimated to be 1.5 to 2.5 million people (4). Furthermore, numerous studies demonstrate that the rate prevalence of hepatitis $\mathrm{B}$ infection can differ amongst the provinces of Iran $(4,5)$.

Though the viral load of the hepatitis B surface antigen (HBsAg) in dialysis patients remains low and stable over time, the prevalence of a hepatitis $B$ virus (HBV) infection in dialysis centers in developing countries is between 2 and $20 \%$ (6). Interestingly, one of the leading causes of HBV in adult hemodialysis patients dates back to occult HBV infection (OBI) (7). OBI is described as the lack of HBsAg in serum, despite the presence of HBV DNA in the liver and peripheral blood 
mononuclear cells (PBMCs), or additional HBV antibodies and antigens (8). Though, anti-HBc and anti-HBs are not detectable during an OBI seronegative HBV infection, an OBI seropositive $\mathrm{HBV}$ infection may be scrutable by the presence of anti-HBc and anti-HBs (1). The underlying cause of OBI may be due to low viral replication, and the strength of the patient's immune response, other concomitant infections, or a mutation that affects the expression of viral antigens (9).

$\mathrm{OBI}$ is among the most common transmissible diseases, through transplantation and transfusion, that can cause cirrhosis and liver cancer (8). Specifically, hemodialysis patients are at a higher risk of OBI, not only from the large amount of blood received, injections and invasive procedures, but due to the suppression of the immune system as well (10). Most importantly, many of these patients will become exposed to HBV during their routine hospital visits. Various reasons could account for their increased risk, including the placement of hepatitis patients in hemodialysis units together with hemodialysis patients either short-term or long-term, exposure to contaminated blood products, sharing of hemodialysis equipment, skin damage, prior immunodeficiencies and vaccination status, which is considered to be less than 50\% amongst hemodialysis patients in any single ward $(11,12)$. Hemodialysis patients require ongoing dialysis due to impaired or non-functional kidneys (13), putting them at an increased likelihood of contracting opportunistic HBV infections (12). According to the literature, the prevalence of OBI in dialysis patients varies between 0 and $36 \%$ (10). In a study conducted by Kivani et al., the prevalence of OBI in hemodialysis patients was reported to be $4.49 \%$ (14). The present investigation was conducted to estimate the prevalence of $\mathrm{OBI}$ and anti-HBc in hemodialysis patients, in hopes of improving the quality of life of these patients in hospitals of Zanjan, Iran.

\section{Materials and methods}

The study was conducted at the Vali-e-Asr Hospital in Zanjan, Iran on $166 \mathrm{HBsAg}$ negative hemodialysis patients, between March of 2015 to September of 2016. This study was approved by the Ethical Committee of Zanjan University of
Medical Sciences (No. ZUMS.REC.1395.83). We collected data, from patient records, including the patients' age, sex, duration of dialysis, history of vaccination, transfusion, and liver enzyme test results (ALT and AST). Then, we collected $10 \mathrm{ml}$ of blood and transferred the vials to the technical department for centrifugation and serum separation. Anti-HBc assays were performed on samples that were HBsAg negative using an ELISA (Dia.pro, Italy). OBI was evaluated using seropositive (anti-HBc and anti-HBs) and seronegative (anti-HBc and anti-HBs) using Nested PCR. The current study also was approved by the Ethical Committee of Zanjan University of Medical Sciences NO. ZUMS.REC.1395.83.

\section{DNA extraction}

Patient DNA was extracted from $200 \mathrm{ul}$ serum samples according to the manufacturer's manual (South Korea, Exgene Cell SV- mini), and stored at $-20{ }^{\circ} \mathrm{C}$ for nested PCR.

\section{Nested PCR}

We used nested PCR to amplify the viral genome. Two pairs of internal and external primers were used to target the S-region of the HBV genome. The specific primer sequences used can be accessed in Table 1. The first reaction consisted of the following mixture: Taq DNA Polymerase 2x Master Mix RED (Ampliqon, Denmark), 0.2 ul from external primers (Table 1), sterilized water and $2 \mathrm{ul}$ from the extracted DNA sample. The final volume was $20 \mathrm{ul}$. The second reaction consisted of the following mixture: Taq DNA Polymerase $2 x$ Master Mix RED (Ampliqon, Denmark), 0.2 ul from internal Primers (Table 1), sterilized water and $0.5 \mathrm{ul}$ from the first reaction product. Both the first and second reactions were performed under the following conditions: initial denaturation at $94{ }^{\circ} \mathrm{C}$ for 5 minutes, 40 cycles at $94{ }^{\circ} \mathrm{C}$ for 30 seconds, $60{ }^{\circ} \mathrm{C}$ for 30 seconds, 72 ${ }^{\circ} \mathrm{C}$ for 30 seconds and the final incubation was performed at $72{ }^{\circ} \mathrm{C}$ for 5 minutes. For all steps, distilled water was used as a negative control, and patient DNA with chronic HBV was used as the positive control. The product from the second reaction was electrophoresed on $2 \%$ agarose gel and the results were analyzed using Gel Doc. 
Table 1. Primers used in Nested PCR.

\begin{tabular}{ccccc}
\cline { 2 - 5 } & Primers & Sequence $\left(\mathbf{5}^{\prime} \boldsymbol{\rightarrow} \mathbf{3}\right.$ ') & PCR product size (Pair) & Reference \\
\hline External & S1-F & CATCAGGATTCCTAGGACCCCT & 311 & 1 \\
primers & S3-R & AGGACAAACGGGCAACATAC & \multirow{2}{*}{1} \\
\hline Internal & S2-F & CTTGTTGACAAGAATCCTCACA & 227 & 1 \\
primers & S4-R & CCAACAAGAAGATGAGGCATA & & \multirow{2}{*}{. } \\
\hline
\end{tabular}

\section{Statistical analysis}

Data obtained from the ELISA and nested PCR were analyzed using SPSS 16 software. Chi-square test was applied to determine the association between nominal data. We utilized the Fisher exact test, when the frequency of a cell in contingency (cross-tab) tables was zero. To compare the continuous data between two groups we applied the Student t-test if the related data had a normal distribution, otherwise we utilized Mann-Whitney test. Furthermore, ANOVA or Kruskal-Wallis tests were performed to compare the data among more than two groups, when the associated data had a normal or non-normal distribution, respectively. The significant level for all analyses was considered less than 0.05 .

\section{Results}

After extracting critical data from the hospital's patient records, our analysis showed that $58.4 \%$ (97) of patients were male, while $41.6 \%$ (69) were female. We found that the mean age of our cohort, in years, was $58.89 \pm 15.49$, and that prior to this study, this group had already undergone $28.27 \pm 27.43$ years of dialysis treatment. In addition, 5.4\% (9) of patients had blood infusion, and $58.4 \%$ (97) had been vaccinated against the hepatitis B virus (HBV). 39 (23.5\%) patients were anti-HBc positive and $127(76.5 \%)$ patients were anti-HBc negative. Moreover, 110 (66.3\%) patients tested positive for anti-HBs and $56(33.7 \%)$ patients were anti-HBs negative. According to the serological patterns against $\mathrm{HBV}$, understudy patients were categorized into four subgroups including $\mathrm{HBs} \mathrm{Ab}-/ \mathrm{HBc} \mathrm{Ab}-, \mathrm{HBs} \mathrm{Ab}-/ \mathrm{HBc} \mathrm{Ab}+$, $\mathrm{HBs} \mathrm{Ab}+/ \mathrm{HBc} \mathrm{Ab}-$, HBs $\mathrm{Ab}+/ \mathrm{HBc} \mathrm{Ab}+$. We, then, looked at the prevalence of these serologic markers and found that there was no significant correlation to the patients' age, sex, duration of dialysis, vaccination against $\mathrm{HBV}$, and history of transfusion (Table 2). Interestingly, ten patients had OBI (Fig. 1, Table 3). We found that the prevalence of OBI in seronegative-OBI individuals were higher compared to seropositive-OBI individuals, and HBV DNA was not detected in $\mathrm{HBc} \mathrm{Ab}+$ individuals. The total number of anti-HBc+ and anti-HBs+ patients was 31, 29 of which, were HBV DNA negative, which relates back to their previous history of $\mathrm{HBV}$ infection. In our cohort study we observed $94.9 \%$ immunized patients against HBV (positive for anti$\mathrm{HBs}$ and negative for HBV DNA) (Table 4). Although, there was no correlation between the prevalence of OBI to the patients' age, sex, duration of dialysis, or history of transfusion, there was a significant correlation between the prevalence of OBI and vaccination status of patients $(\mathrm{p}<0.011)$. Overall, we found that the prevalence of OBI in patients who received the HBV vaccine was lower than those who did not receive the vaccine (Table 4).

Table 2. The descriptive results of HBV serologic patterns with duration of dialysis, history of blood transfusion and vaccination.

\begin{tabular}{|c|c|c|c|c|c|c|}
\hline \multicolumn{2}{|l|}{ Variables } & $\begin{array}{l}\text { HBsAb-/ } \\
\text { HBcAb- }\end{array}$ & $\begin{array}{l}\text { HBsAb-/ } \\
\text { HBcAb+ }\end{array}$ & $\begin{array}{l}\text { HBsAb+l } \\
\text { HBcAb- }\end{array}$ & $\begin{array}{l}\text { HBsAb+l } \\
\text { HBcAb+ }\end{array}$ & $\mathrm{p}<0.05$ \\
\hline \multicolumn{2}{|c|}{$\begin{array}{l}\text { Frequency of HBV serological patterns: } \mathrm{n} \\
(\%)\end{array}$} & $48(28.9)$ & $8(4.8)$ & $79(47.6)$ & $31(18.7)$ & \\
\hline \multicolumn{2}{|c|}{ Average age of patients (Means $\pm \mathrm{SD}^{\epsilon}$ ) } & $61.29 \pm 15.0$ & $61.62 \pm 6.88$ & $57.93 \pm 16.32$ & $59.93 \pm 15.67$ & $* 0.883$ \\
\hline \multirow{2}{*}{$\begin{array}{l}\text { Gender: } \\
\mathrm{n}(\%)\end{array}$} & Male & $29(29.9 \%)$ & $3(3.1 \%)$ & $49(50.5 \%)$ & $16(16.5 \%)$ & \multirow{2}{*}{$£ 0.469$} \\
\hline & Female & $19(27.5 \%)$ & $5(7.2 \%)$ & $30(43.5 \%)$ & $15(21.7 \%)$ & \\
\hline \multicolumn{2}{|c|}{ Duration of dialysis (Means \pm SD) } & $19.72 \pm 16.67$ & $44.50 \pm 30.76$ & $31.50 \pm 29.21$ & $29.09 \pm 32.38$ & $* 0.210$ \\
\hline \multirow{2}{*}{$\begin{array}{l}\text { History of blood } \\
\text { receiving: } \\
\mathrm{n}(\%)\end{array}$} & Yes & $2(22.2 \%)$ & - & $5(55.6 \%)$ & $2(22.2 \%)$ & \multirow{2}{*}{$* * 0.886$} \\
\hline & No & $46(29.3 \%)$ & $8(5.1 \%)$ & $74(47.1 \%)$ & $29(18.5 \%)$ & \\
\hline \multirow{2}{*}{$\begin{array}{l}\text { Vaccination: } \\
\mathrm{n}(\%)\end{array}$} & Yes & $29(29.9 \%)$ & $3(3.1 \%)$ & $50(51.5 \%)$ & $15(15.5 \%)$ & \multirow{2}{*}{$£ 0.850$} \\
\hline & No & $19(27.5 \%)$ & $5(7.2 \%)$ & $29(42 \%)$ & $16(23.2 \%)$ & \\
\hline
\end{tabular}

* Kruskal-wallis test was used. $£$ Chi-square test was used.

** Fischer exact test was used. ${ }^{€}$ Standard deviation test was used. 
Table 3. Demographic information of negative and positive HBV DNA patients.

\begin{tabular}{|c|c|c|c|c|}
\hline \multicolumn{2}{|l|}{ Variables } & HBV DNA+ & HBV DNA- & $\mathrm{p}<0.05$ \\
\hline \multicolumn{2}{|c|}{ Average age of patients (Means \pm SD) } & $60.70 \pm 14.00$ & $58.78 \pm 15.61$ & 0.946 \\
\hline \multirow{2}{*}{ Gender: n $(\%)$} & Male & $4(4.1 \%)$ & $93(95.9 \%)$ & \multirow{2}{*}{0.222} \\
\hline & Female & $6(8.7 \%)$ & $63(\% 91 / 3)$ & \\
\hline Duration of dialysis (Means \pm SD) & & $30.80 \pm 22.26$ & $28.11 \pm 27.78$ & 0.387 \\
\hline \multirow{2}{*}{ History of blood receiving: $\mathrm{n}(\%)$} & Yes & - & $9(100 \%)$ & \multirow{2}{*}{0.435} \\
\hline & No & $10(6.4 \%)$ & $147(93.6 \%)$ & \\
\hline \multirow{2}{*}{ HBV vaccination: $\mathrm{n}(\%)$} & Yes & $2(2.1 \%)$ & $95(97.5 \%)$ & \multirow{2}{*}{0.011} \\
\hline & No & $8(11.6 \%)$ & $61(88.4 \%)$ & \\
\hline
\end{tabular}

Table 4. Identification of HBV DNA among Negative HBsAg Hemodialysis Patients with diverse Serological Patterns of HBV.

\begin{tabular}{lllll}
\hline \multirow{2}{*}{ Diverse Serological Patterns of HBV } & Patients & Occult HBV DNA+ & Occult HBV DNA- & \multirow{2}{*}{$\mathbf{0}<\mathbf{0 5}$} \\
\cline { 2 - 4 } & $\mathbf{n}(\%)$ & $\mathbf{N}(\%)$ & $44(91.7)$ & \\
\hline $\mathrm{HBs} \mathrm{Ab}-/ \mathrm{HBc} \mathrm{Ab}-$ & $48(28.9)$ & $4(8.3)$ & $8(4.8)$ & 0.857 \\
$\mathrm{HBs} \mathrm{Ab}-/ \mathrm{HBc} \mathrm{Ab}+$ & $8(4.8)$ & & $75(94.9)$ & \\
$\mathrm{HBs} \mathrm{Ab}+/ \mathrm{HBc} \mathrm{Ab}-$ & $79(47.6)$ & $4(5.1)$ & $29(93.5)$ & \\
$\mathrm{HBs} \mathrm{Ab}+/ \mathrm{HBc} \mathrm{Ab}+$ & $31(18.7)$ & $2(6.5)$ & $156(94)$ & \\
\hline Total & $166(100)$ & $10(6)$ & &
\end{tabular}

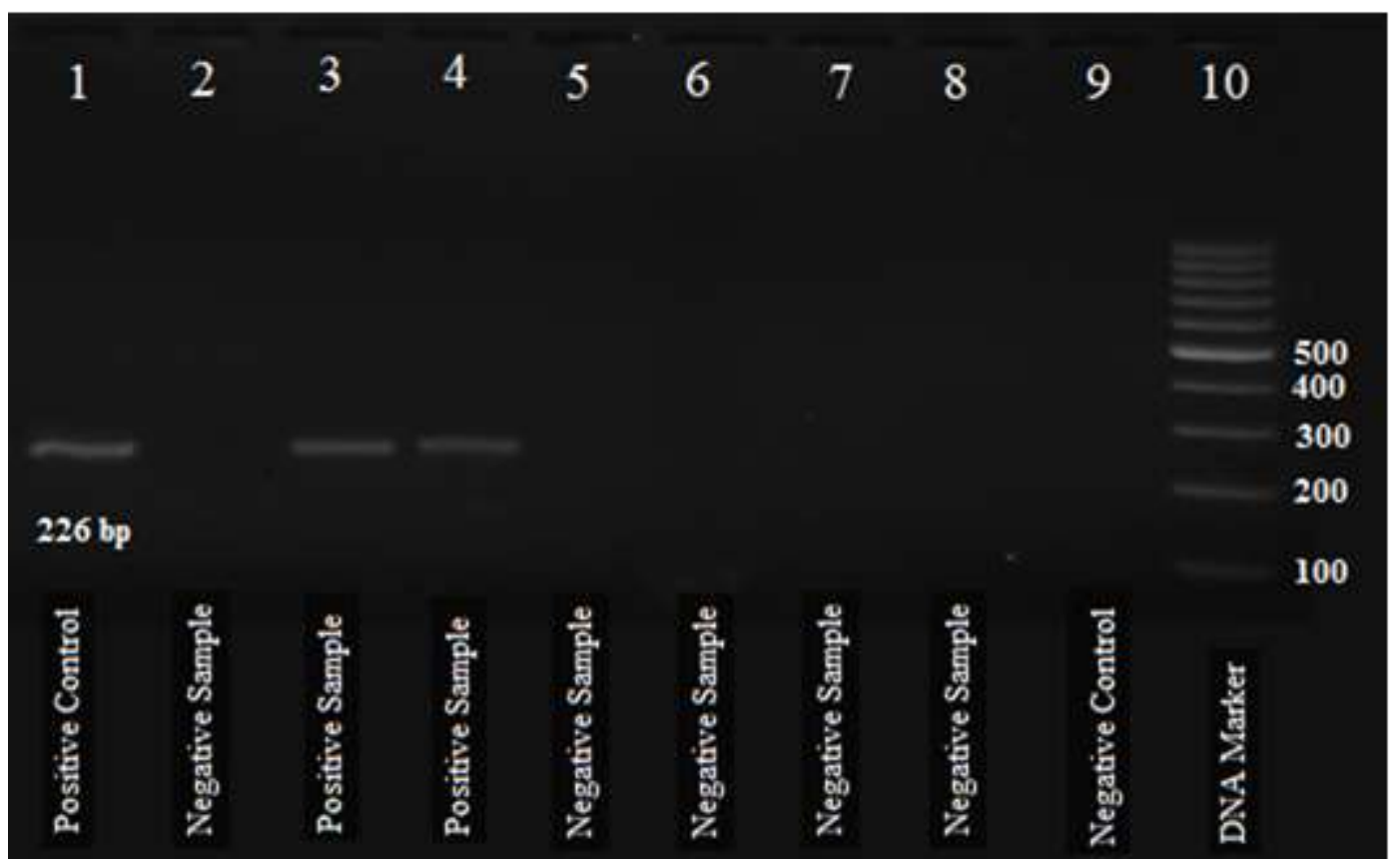

Fig. 1. Electrophoresis of Nested PCR product on agarose gel. Lane 1: positive control, lanes 2 to 8 samples, lane 9 is negative control, and lane 10 is DNA ladder. Samples 3 and 4 are positives show a 226-bp amplicon.

\section{Discussion}

OBI is characterized by the number of HBV DNA copies in the serum, in the absence of HBsAg, and regardless of the presence of other serological HBV markers, including anti-HBs and anti-HBc. Moreover, OBI patients are categorized as either seropositive-OBI or seronegative-OBI (15). The present study investigated seronegative and seropositivity of HBV markers in hemodialysis patients. Based on previous studies, $20 \%$ of individuals with OBI were seronegative and $80 \%$ were seropositive (15). In our study, only $20 \%$ of OBI cases were seropositive. Additionally, $6 \%$ of hemodialysis patients had OBI. Similar to our findings, Esmat et al. demonstrated that the prevalence of $\mathrm{OBI}$ in negative and positive HCV RNA cases were $6 \%$ and $8 \%$, respectively (16). A North American study led by Minuk et al. reported the prevalence of OBI as 3.8\% in seropositive cases (17). Similar to our observations, the prevalence of OBI was 
higher in seronegative patients. The difference in results may be related to the fact that North America is classified as a hypoendemic region, in regards to the prevalence of HBV (18). In contrast, Hashemi et al. reported the prevalence of OBI as $11 \%$ (19). This difference could be linked to the duration of dialysis, which according to their observations, was $47.46 \pm 27.78$, compared the duration of hemodialysis in our study, which was $28.27 \pm 27.43$. Further, the difference in prevalence (15) in their study could be related to the prevalence of $\mathrm{HBsAg}$, which was reported to be between 7 and 16\% (19). Similar to our study, the prevalence of OBI in seronegative individuals was higher than in seropositive individuals. Rastegarvand et al. found that $2.3 \%$ of hemodialysis patients had OBI (20). In another study led by Neisi et al, the prevalence of OBI was determined to be $4 \%$ (21). Ramazani et al. reported the prevalence of isolated anti-HBc as $2 \%$ and $\mathrm{OBI}$ as $1 \%$ and further identified OBI to be prevalent in isolated anti-HBc+ individuals (22). To account for this difference, in comparison to our study, we speculated that the type of population could play a profound role. Jardim et al. investigated the prevalence of OBI in HBsAg negative hemodialysis patients and the prevalence of anti-HBc+, anti-HBs+, and anti-HBc+ serologic markers, which was reported to be $0 \%$, similar to our findings (23). Furthermore, Tabrizi et al. reported the prevalence of OBI as $0 \%$ among hemodialysis patients with a history of receiving the $\mathrm{HBV}$ vaccine, however, in our study, the prevalence of OBI in hemodialysis patients receiving the $\mathrm{HBV}$ vaccine was only $1.2 \%$ (24). The reason for this difference could be related to the efficacy of vaccines, the frequency and timing of vaccination. Since dialysis patients are typically older and the efficacy of vaccines

\section{References}

1. Raimondo G, Allain JP, Brunetto MR, Buendia MA, Chen DS, Colombo M, et al. Statements from the Taormina expert meeting on occult hepatitis B virus infection. J Hepatol. 2008;49(4):652-7.

2. Fattovich G, Bortolotti F, Donato FJJoh. Natural history of chronic hepatitis B: special emphasis on disease progression and prognostic factors. J Hepatol. 2008;48(2):335-52. and dialysis declines with age, the number of OBI cases were expected $(25,26)$. The results could also be influenced by the sensitivity and specificity of the methods used (22). In another investigation led by Fabrizi et al, the prevalence rate of $\mathrm{OBI}$ in positive anti-HBc samples was reported to be $0 \%$, similar to the results of our study (27). Conversely, Zaki MS et al. reported the prevalence of OBI to be $18.8 \%$ in hemodialysis patients, which we found to be the greatest prevalence rate of HBV DNA in patients negative for serologic HBV markers (28). In this particular study, they also found a significant relationship between $\mathrm{OBI}$ and duration of dialysis, which, consequently, would increase the probability of OBI. Lastly, Fontenele et al. reported the prevalence rate of OBI to be $2.3 \%$ in hemodialysis patients, all of which, received four doses of the HBV vaccine (29). Furthermore, there was a significant correlation between the outcome of their study with our present study.

We found that the prevalence of OBI was $6 \%$ in patients undergoing hemodialysis. There was no significant relationship between the prevalence of OBI to the patients' age, sex, duration of dialysis, and history of blood transition. However, there was a significant relationship between vaccination and the prevalence of OBI. Regarding the prevalence of OBI in the dialysis center, we recommend that OBI be screened together with HBsAg hepatitis $\mathrm{B}$ in hemodialysis patients.

\section{Acknowledgment}

This work as an MSc thesis in Medical Microbiology was supported by the Zanjan University of Medical Sciences (A-12-864-6).

The authors declare that they have no conflict of interest.

3. Lok ASF, McMahon BJ, Practice Guidelines Committee, American Association for the Study of Liver Diseases (AASLD). Chronic hepatitis B: update of recommendations. Hepatology.2004;39(3):857-61.

4. Hou J, Liu Z, Gu F. Epidemiology and prevention of hepatitis B virus infection. Int J Med Sci. 2005;2(1):50-57. 
5. Alavian SM, Hajarizadeh B, Ahmadzad-Asl M, Kabir A, Bagheri-Lankarani KJHm. Hepatitis B Virus infection in Iran: A systematic review. Hepatitis Monthly. 2008;8(4).

6. Fabrizi F, Messa P, Martin P. Hepatitis B virus infection and the dialysis patient. Semin Dial. 2008;21(5):440-6.

7. Brechot C, Thiers V, Kremsdorf D, Nalpas B, Pol S, Paterlini-Brechot P. Persistent hepatitis B virus infection in subjects without hepatitis B surface antigen: clinically significant or purely “occult"?. 2001;34(1):194-203.

8. Martinez MC, Kok CC, Baleriola C, Robertson $\mathrm{P}$, Rawlinson WD. Investigation of occult hepatitis $B$ virus infection in anti-hbc positive patients from a liver clinic. PLoS One. 2015;10(3):e0117275.

9. Motta JS, Mello FC, Lago BV, Perez RM, Gomes SA, Figueiredo FF, et al. Occult hepatitis B virus infection and lamivudine-resistant mutations in isolates from renal patients undergoing hemodialysis. J Gastroenterol Hepatol. 2010;25(1):101-6.

10. Gutierrez-Garcia ML, Fernandez-Rodriguez CM, Lledo-Navarro JL, Buhigas-Garcia I. Prevalence of occult hepatitis B virus infection. World J Gastroenterol. 2011;17(12):1538-42.

11. Chan T-M, Schwab SJ, Hirsch MS. Hepatitis B virus and dialysis patients. https://www.uptodate.com/contents/hepatitis-bvirus-and-dialysis-patients.

12. Edey M, Barraclough K, Johnson DW. Review article: Hepatitis $\mathrm{B}$ and dialysis. 2010;15(2):137-45.

13. Mohammadalizadeh AH, Ranjbar M, Seyf Aleslami SAR. The frequency of Hepatitis $C$ in dailyse patients in HAMADAN EKBATAN hospital. 2002;7:27-34.

14. Aghakhani A, Banifazl M, Kalantar E, Eslamifar A, Ahmadi F, Razeghi E, et al. Occult hepatitis $\mathrm{B}$ virus infection in hemodialysis patients with isolated hepatitis B core antibody: a multicenter study. Ther Apher Dial. 2010;14(3):349-53.

15. Ramezani A, Aghasadeghi MR, Ahmadi F, Razeghi E, Eslamifar A, Banifazl M, et al. Isolated anti-hbc and occult HBV infection in dialysis patients. Nephrourol Mon. 2015;7(1): e22674.
16. Esmat MM, Mohamed T, Zazi NAE. Occult Hepatitis $b$ virus infection among Egyptian hepatitis c virus seropositive and seronegative hemodialysis patients in Sohag government, upper Egypt. Egyptian Journal of Medical Microbiology. 2015;24:113-118.

17. Minuk GY, Sun DF, Uhanova J, Zhang M, Caouette S, Nicolle LE, et al. Occult hepatitis B virus infection in a North American communitybased population. J Hepatol. 2005;42(4):480-5.

18. Aghakhani A, Banifazl M, Velayati AA, Eslamifar A, Ramezani AJTA, Dialysis. Occult hepatitis B virus infection in hemodialysis patients: a concept for consideration. 2012;16(4):328-333 .

19. Hashemi SJ, Hajiani E, Masjedizadeh A, Makvandi M, Shahbazian H, Shayesteh A, et al. A Case-Control Study on Occult Hepatitis B Infection in Chronic Hemodialysis Patients from South-West of Iran. 2015;20(1):135-40.

20. Rastegarvand N, Makvandi M, Samarbafzadeh A, Rasti M, Neisi N, Pouremamali A, et al. Molecular Characterization of Pre-Core/Core and S Region of Hepatitis B Virus in Hemodialysis Patients with Occult Hepatitis B Infection. Jundishapur J Microbiol. 2015;8(10):e23686.

21. Neisi N, Makvandi M, Ali Samarbaf-Zadeh R. A study on genotypes of hepatitis B virus among hemodialysis patients in Khuzestan province. Jundishapur journal of microbiology. 2011;4(2):65-70.

22. Ramezani A, Aghasadeghi MR, Ahmadi F, Razeghi E, Eslamifar A, Banifazl M, et al. Isolated anti-HBc and occult HBV infection in dialysis patients. Nephro-urology monthly. 2015;7(1):e22674.

23. Jardim RNCM, Gonçales NSL, Pereira JSF, Fais VC, Gonçales Junior FL. Occult hepatitis B virus infection in immunocompromised patients. Braz J Infect Dis. 2008;12(4):300-5.

24. Abbasi A, Tajbakhsh R,Kabotari M, Zhand S, Tabarraei A. Occult Hepatitis B Virus Infection in Chronic Hemodialysis Patients in Panje-Azar Hospital, Gorgan. Medical Laboratory Journal. 2012;6(1):7-12.

25. Mustafa HNAR, Ahmad LM, Hassan ANL. Update on prevalence, diagnosis and treatment of hepatitis B virus. Faculty of Medicine Cairo University. 2005. 
26. Fabrizi F, Dixit V, Bunnapradist S, Martin P. Meta-analysis: the dialysis mode and immunological response to hepatitis $\mathrm{B}$ virus vaccine in dialysis population. Aliment Pharmacol Ther. 2006;23(8):1105-12.

27. Fabrizi F, Messa PG, Lunghi G, Aucella F, Bisegna S, Mangano S, et al. Occult hepatitis B virus infection in dialysis patients: a multicentre survey. Alimentary pharmacology \& therapeutics. 2005;21(11):1341-7.
28. Zaki MES, Rafaat D, Eliwa A, Abdelsalam M. Occult hepatitis B among patients under hemodialysis at Mansoura University Hospitals: prevalence and risk factors. J Virol Antivir Res. 2014;3(1):1-6.

29. Fontenele AMM, Gainer JBF, e Silva S, Viana D, Cruz Santos MD, Salgado JV, et al. Occult hepatitis B among patients with chronic renal failure on hemodialysis from a capital city in northeast Brazil. Hemodial Int. 2015;19(3):353-9. 